\title{
UNDERSTANDING WHAT NUMBERS MEAN
}

\author{
Britton, M. G. (Ron) \\ Faculty of Engineering, University of Manitoba, Winnipeg, Manitoba, R3T 5V6
}

\section{INTRODUCTION}

As instructors we expect our students to understand what the numbers they generate "mean". We expect them to be able to visualize, in real or virtual terms, some physical approximation of the "things" they are working with. This visualization provides the basis for a "logic check" on their calculations.

Our profession is founded on our ability to specify, within imposed constraints, the physical and functional characteristics of a system that will provide a safe, affordable solution to a problem. Students need to develop and refine this capacity during their undergraduate education. As simple as that may seem to those of us who have experienced the realities of our particular areas of expertise, it is not intuitive. Virtually all academic engineers lament the fact that students regularly submit answers that make no physical sense. The twin questions this issue raises are:

1. why do so many students seem to lack an understanding of what their computer generated numbers mean?, and

2. how can we help them gain the understanding we want them to have? THE LEARNING ENVIRONMENT

Our typical learning environment is driven by Bloom's Taxonomy (1). What many persons do not realize is that Bloom defined three learning domains, the Cognitive, the Affective and the PsychoMotor. In Engineering, we tend to concentrate on the Cognitive Domain in which he classifies the learning sequence moving from a "knowledge" base up to an "evaluation" apex. It is a progression that builds from memory through to creating. The Affective domain relates to values and covers the range of simply accepting information to evaluating, not analysing, the information that is presented. The Psycho-Motor Domain, which Bloom never fully developed, relates to skill development and physical understanding.

Simplistically the three domains can be identified as "facts", "feelings" and " function". Each represents a sequential listing of learning objectives within that particular sphere. While engineering education is dominantly in the Cognitive Domain, the new CEAB Attributes (2) are more related to the Affective Domain, and understanding the "reality" of numbers requires that attention be paid to the Psycho-Motor approach.

If we want our students to understand and respect the physical reality of the numbers they generate in response to questions we pose, we need to incorporate components of these later two Taxonomies into our course delivery. In particular, we need to find ways to incorporate physical experience into our learning environment.

\section{SHOWING THE OBVIOUS}

For most students, particularly those who have developed their understanding of the world through video games and video illustrations, measurements are just numbers. In my world of building design, is it reasonable to expect that students have an appreciation for a "square" of shingles, a "yard" of "fill", or the real dimensions of a 2 by 4 ? These are jargon terms that represent real values in my mind. I can "feel" the weight and "visualize" the size. I learned about them through the trial and error of lifting, estimating and measuring. I evaluate my calculations in the light of that Psycho-Motor learning. Don't our students need that same opportunity?

\section{AN EXPERIMENT THAT WORKED}

A number of years ago, while teaching a course in light frame building design, I had two major concerns relating to student background. First, few, if any, of my students had ever been involved in a building project. Second, even fewer students had a physical understanding of the magnitude of loads, particularly snow loads, a critical element in light frame building design. I decided to use the first three laboratory periods in an attempt to address these concerns. Typically those periods were filled with "busy work" until the theories upon which the course was based had been developed sufficiently for meaningful design problems to be assigned.
Students were divided into teams of three. Each team was assigned a "building site" in the structures laboratory. Their assignment was to build a $1 / 8$ th scale post-frame building. They were provided with a complete set of plans for a full scale post-frame building, a simplified, illustrated handout on the basics of post-frame construction and a $1 / 8$ th scale "tape". The "tape" allowed them to work directly with measurements specified on the drawings. The laboratory was stocked with a supply of $1 / 8$ th scale lumber/plywood that we "produced" from scrap lumber and poster board. Students had access to hand tools. The only concession to $1 / 8$ th scale reality was the use of glue guns rather than nails. Laboratory periods were supervised to provide answers to questions, not instruction.

Over the three week period, students learned post-frame building jargon. A laboratory exercise that was initially seen as trivial quickly became a serious undertaking. They mastered the basic use of carpenters squares, they learned that drawing dimensions were critical, they layed out and squared up their buildings at ground level, they addressed the problems of "re-squaring" the buildings at eave level. During building "commissioning" they suggested that the most important lesson learned was a respect for the skills of those who will be responsible for the construction of buildings they will desig in the future.

Beginning in the second laboratory period, and simultaneously with the building assignment, the snow load experience was introduced. The process was based on a $0.5 \mathrm{~m}^{2}$ panel, of known mass, with six extended lifting arms to allow all three students to experience the "lift". The panel was placed on sawhorses in the laboratory. Each team was given a list of ground snow loads, in $\mathrm{kN} / \mathrm{m}^{2}$, that they were required to simulate. Loads were created using $10 \mathrm{~kg}$ "suitcase" weights. After each load was assembled, the student team physically lifted the panel. In this way they gained a physical understanding of the numbers they would ultimately work with. Students were encouraged to "play" with the system to increase their "feel" for distributed loads. One of the selected loads was, in fact, less that the dead load of the panel. This immediately created discussions around the difference between dead loads and live loads, no "lecture" required. As simplistic as this "weight lifting lab" may seem, it solved what had been a long standing problem of design assignments in which snow loads were calculated to several decimal places. Students seemed to gain an understanding of the distinction between accuracy and precision.

SUMMARY

The preceding example is not intended as a recommended procedure, but rather an illustration of a Psycho-Motor based exercise that addressed, in that particular class, the problem of improved understanding. It did not require significant investment, but rather the use of items at hand to create an physical learning opportunity. Similar Psycho-Motor type experiences can undoubtedly be developed for most Engineering Science courses.

As instructors we strive to assure that our students gain a level of competence in using the theories that are basic to our courses. Recognizing the "reality" of numbers produced using those theories is basic to the competence the students require. It is our responsibility to provide students with learning beyond the theoretical.

\section{REFERENCE}

1. Bloom's Taxonomy, http://www.learningandteaching.info/learning/bloomtax.htm

2. Canadian Engineering Accreditation Board, 2010 Accreditation Criteria and Procedures, Canadian Council of Professional Engineers. 2010 